NASA Technical Memorandum 102425

\title{
An Investigation of Flame Spread Over Shallow Liquid Pools in Microgravity and Nonair Environments
}

\author{
(NASA-TM-102425) AN INVESTIGATION OF FLAME \\ N90-13680 \\ SPREAO OVER SHALLTW LI ZUIO POOLS IN \\ MICROGRAVITY AND NONAIR ENVIRONMENTS (NASA) \\ $19 \mathrm{p}$ \\ CSCL 218 \\ $\begin{array}{ll}\text { Unclas } \\ 93 / 29 & 0252613\end{array}$
}

Howard D. Ross and Raymond G. Sotos

Lewis Research Center

Cleveland, Ohio

Prepared for the

23rd International Symposium on Combustion

sponsored by The Combustion Institute

University of Orleans, France, July 22-27, 1990 


C

$\therefore \quad \therefore \quad \therefore \quad$;

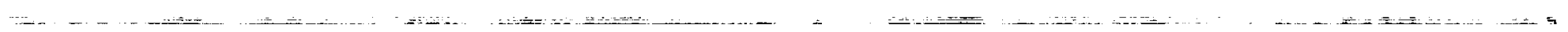

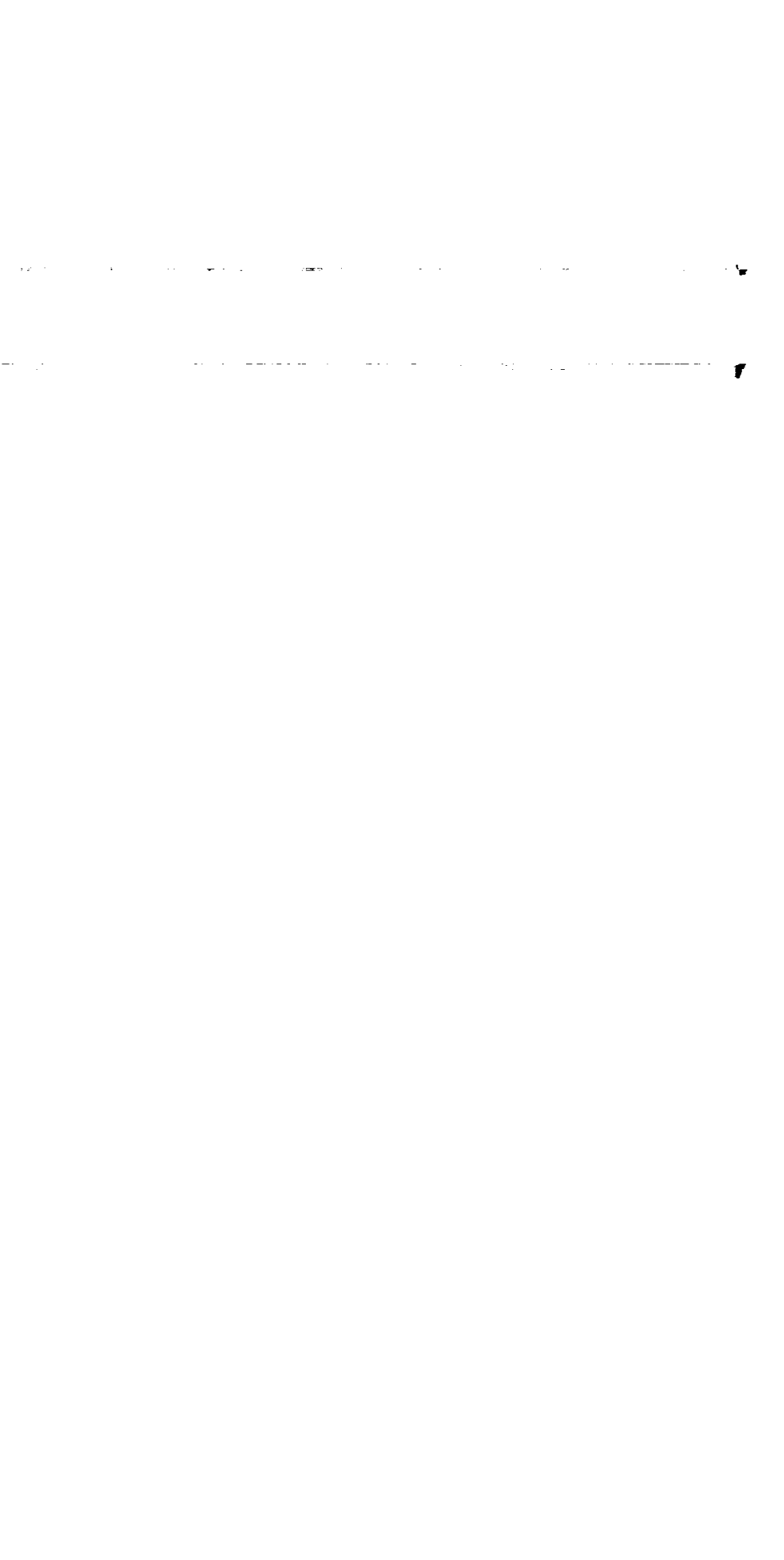

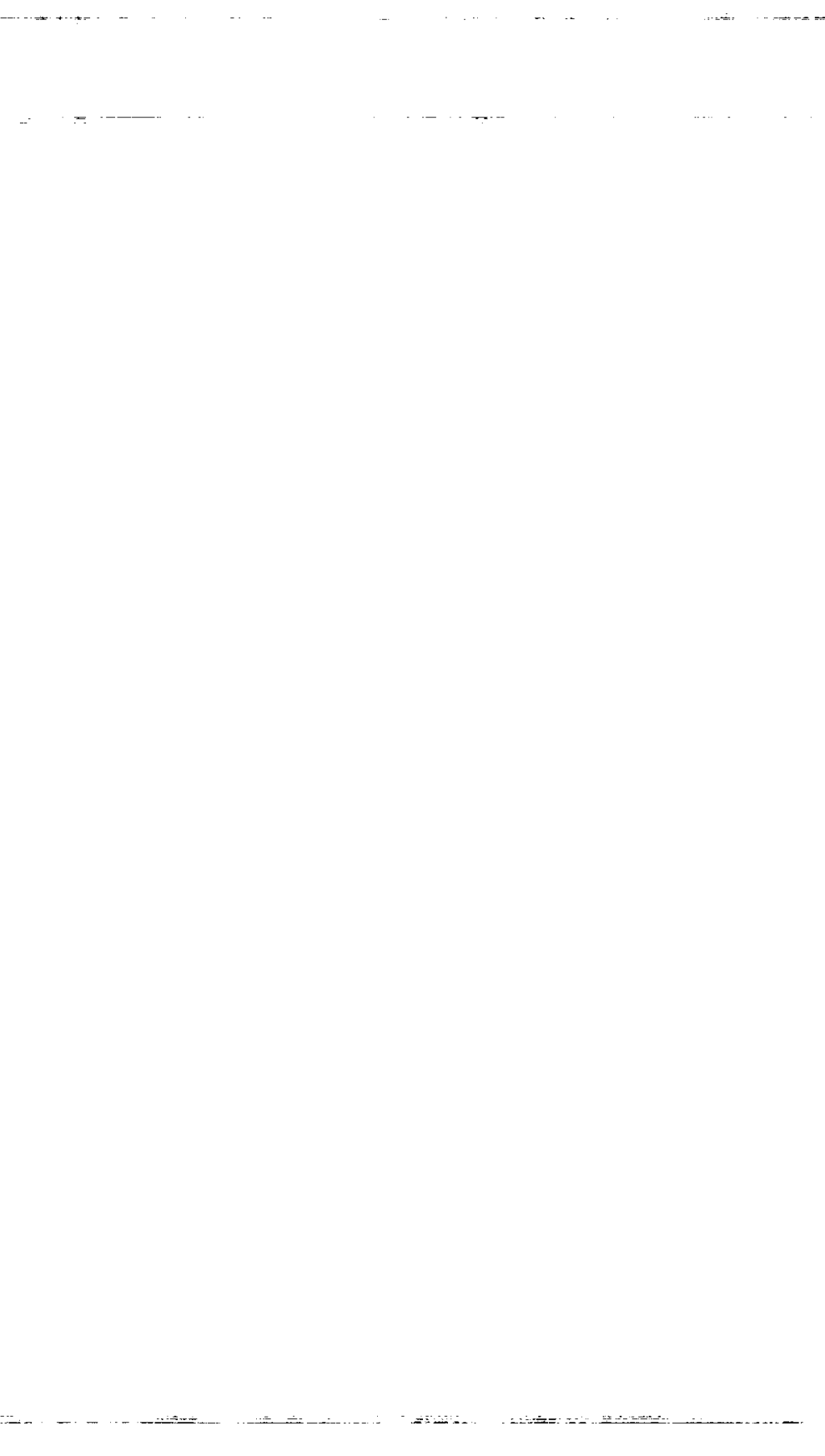




\title{
AN INVESTIGATION OF FLAME SPREAD OVER SHALLOW LIQUID POOLS IN

\author{
MICROGRAVITY AND NONAIR ENVIRONMENTS
}

\author{
Howard D. Ross and Raymond G. Sotos \\ National Aeronautics and Space Administration \\ Lewis Research Center \\ Cleveland, Ohio 44135
}

\begin{abstract}
Experiments of interest to combustion fundamentals and spacecraft fire safety investigated flame spread of alcohol fuels over shallow, 15-cm diameter pools in a $5.2 \mathrm{sec}$ free-fall, microgravity facility. Results showed that, independent of $\mathrm{O}_{2}$ concentration, alcohol fuel and diluent types, microgravity flame spread rates were nearly identical to those corresponding normal-gravity flames for conditions where the normal-gravity flames spread uniformly. This simllarity indicates buoyancy-related convection in either phase does not affect flame spread, at least for the physical scale of the experiments. However, microgravity extinction coincided with the onset conditions for pulsating spread in normal gravity, implicating gas phase, buoyant flow as a requirement for pulsating spread. When the atmospheric nitrogen was replaced with argon, the conditions for the onset of normal-gravity pulsating flame spread and microgravity flame extinction were changed, in agreement with the expected lowering of the flash point through the thermal properties of the diluent. Helium-diluted flames, however, showed unexpected results with a shift to apparently higher flash-point temperatures and high normal-gravity pulsation amplitudes.
\end{abstract}

\section{INTRODUCTION}

Flame spread over liquid fuel pools is commonly characterized by the relationship of the initial pool temperature to the fuel's flash point temperature. Over a range of pool temperatures well below the closed-cup flash temperature, Tcc, pulsating flame spread across the pool surface is observed. At pool temperatures above this range, flame spread is steady ("uniform"l); at temperatures below those inducing pulsating spread, the flame spread is again steady ("pseudouniform").

Widely conflicting explanations of the detailed phenomenology and controlling spread mechanism are found in the literature. For example, when flame spread is uniform and the pool temperature is below $T_{C c}$, control has been attributed to (1) gas phase conduction and radiation, 1 (2) gas phase 
conduction only,2,3 (3) gas phase convection and liquid conduction, 4 and most recently (4) liquid corvection ahead of the flames. 5 The latter, observed by holographic interferometry and convection barriers in $1 \mathrm{~cm}$ deep, propanolfilled narrow trays, is explained as consisting of roughly equal proportions of buoyant and thermocapillary forces.

Several explanations have also been offered for the pulsating regime, 1,5,6 but the most widely accepted is that control varies periodically from premixed gas, layered combustion to diffusive burning across the pulsating front, due to coupled gas/liquid motion.2,3 Buoyancy is believed to contribute significantly to the experimentally-observed, complicated motion in both the liquid and gas phases.

All of the cited experiments were done at normal gravity in a standard air atmosphere, with variations of fuel type and initial temperature only. The ability to predict sub-T $c c$ flame spread behavior in nonair environments, and especially in microgravity, is hindered by the various interpretations of experimental results and by current models which cannot predict the uniform or pulsating flame spread rate, $V_{f}$, under any sub-Tcc condition. Most models assume $V_{f}$, decouple gas phase processes by assuming interfacial boundary conditions, and then calculate the velocity and temperature fields in the liquid phase; 7,8 unfortunately the calculated subsurface fields disagree with the complicated measured motions, and discrepancies are usually attributed to buoyancy effects. One mode ${ }^{9}$ does couple both phases, but it assumes unity Lewis number, fast kinetics, and constant $\mathrm{O}_{2}$ concentration outside the flame sheet, and is therefore inaccurate near the leading edge of the flame. Nonetheless it predicts that the flame position is strongly affected by gas phase buoyancy.

The present experiments on flame spread in microgravity and in nonair environments seek to provide information for both a better understanding of 
the mechanisms of uniform and pulsating flame spread and for applications to improved fire safety in spacecraft environments. Prior to this study, it was not clear under what conditions, if any, ignition and sub-Tcc flame spread could occur in microgravity, and whether pulsating spread would occur in the absence of buoyancy-driven flows.

\section{EXPERIMENT DESCRIPTION}

A series of normal and microgravity experiments were performed in the NASA Lewis Research Center Zero Gravity Facility, a $5.18 \mathrm{sec}$ free-fall drop tower. 10 A $15 \mathrm{~cm}$ diameter, $1.6 \mathrm{~mm}$ deep, ceramic-based tray was mounted inside a 113 liter pressure vessel which permitted the use of selected ambient atmospheres. Ignition was via a hot wire centrally located on a cantilever over the tray; ignition was delayed for $3 \mathrm{sec}$ after the start of free fall to ensure that ignition occurred after initial liquid-motion disturbances were damped. To minimize predrop evaporation, the pool was filled automatically by gravity just before the drop. Multiple safety systems were employed including a spring-loaded pool cover, vacuum venting, and nitrogen pressurization. The simple instrumentation, necessary to meet the rigors of free-fall testing, was top and side view cameras and a thermocouple to determine the initial system temperature. Following the test, the flame spread rate was determined from the visible flame diameter as a function of time through the use of a digitized motion analyzer.

Because temperature was not varied from ambient conditions, the selected fuels were simple alcohols with flash points near ambient temperature. The majority of tests were conducted with n-propanol and n-butanol, for which $T_{C C}$ is approximately 25 and $38^{\circ} \mathrm{C}$, respectively, in a standard air atmosphere.

Some tests were also conducted with 55 percent ethanol and 45 percent distilled water for comparison to the results of Ref. 4, and with super-TCc methanol and ethanol in normal air. Identical normal-gravity tests were run for comparison 
to microgravity tests. In several cases, the normal-gravity test was permitted to continue for several seconds after flame spread in order to observe the postspread, oscillating flame.

A challenging problem with microgravity liquid-gas experiments involves the control of the interfacial surface, whose shape is determined by a balance of gravitational and surface tension forces, i.e., the Bond number, Bo $=\rho g l^{2} / \sigma$, where $\rho$ is the liquid density, $g$ is the gravitational acceleration, 1 is a characteristic vessel dimension, the pool radius in this case, and $\sigma$ is the surface tension. For propanol, Bo, based on radius, is about 1800 in normal gravity and 0.0018 in microgravity. The liquid surface can therefore transition from a flat configuration, dominated by gravitational forces, in normal gravity to one of constant curvature, dominated by surface tension, in microgravity. 11 A flat configuration was successfully maintained in microgravity, however, by filling the liquid fuel to the rim of the knifesharp edge of the tray, where the contact angle is undefined. An overflow channel around the pool permitted safe, complete filling. Nonetheless, it was observed in preliminary tests, that the transition from normal to reduced gravity induced undesirable liquid motion due possibly to a flexure of the apparatus. The short microgravity test time therefore required the use of small dimensioned pools and the more viscous alcohols to reduce the damping time. The shallow pools we subsequently employed had the additional benefits of minimizing the ignition delay time at a pool depth just beyond the unignitable, thin film regime 12 and reducing, in normal gravity, liquid phase buoyancy without affecting gas phase buoyancy. Though the overall diameter is less than ideal, 6 we note, as others have, 1,5 that the spread character appears relatively unaffected by pool length and width. 


\section{RESULTS}

3.1 Norma1-Gravity Oxygen-Nitrogen Atmosphere Tests

The solid lines in Fig. I shows the flame diameter as a function of time for normal-gravity, propanol- $\mathrm{O}_{2}-\mathrm{N}_{2}$, baseline tests. At 30 percent $\mathrm{O}_{2}$ or higher (curve a), the flame shape and spread were immediately well-defined and steady, with the leading edge of the flame stabilized immeasurably close $(<0.5 \mathrm{~mm})$ to the pool surface. The flame was bright yellow, indicating a higher flame temperature and soot production. Flame spread was so rapid that a plume did not develop until the postspread, pool fire was established. For the tests with $\mathrm{O}_{2}$ concentration of normal air (curve b), the flame became blue, the flame spread rate reduced, and the vertical flame plume developed and oscillated axisymmetrically during spread; however, the flame spread rate remained uniform, unaffected by the plume's oscillations. For the tests with the $\mathrm{O}_{2}$ concentration at 18 percent, the transition to pulsating spread began. At $\mathrm{O}_{2}$ concentrations below 18 percent (curve d), the flame spread became slightly asymmetric and clearly pulsating in nature. In each case after spreading, the normal-gravity flames developed the classical, pool burning behavior with an oscillating vertical plume. The $\mathrm{O}_{2}$ concentration did not discernably affect the 3 to $4 \mathrm{~Hz}$ oscillation frequency of the plume.

Since the fire point (and presumably flash point) temperature is affected by $\mathrm{O}_{2}$ concentration, 13 the observed behavior is consistent with expectation, i.e., both temperature and $\mathrm{O}_{2}$ levels affect the character of flame spread, though certain $\mathrm{O}_{2}$-related features - asymmetric propagation and enhanced sooting - augment the characteristic spread regimes on Akita's well-known, temperature-based spread map. I

The same behavior was observed for $\mathrm{N}_{2}$-diluted, n-butanol (see Fig. 2) and ethanol/water flames, but the transition between pulsating-uniform spread regimes occurred at higher $\mathrm{O}_{2}$ concentration (25 percent $\mathrm{O}_{2}$, curve $b$ ). This 
observed behavior was as expected because n-butanol has a higher flash point than n-propanol.

\subsection{Normal-Gravity Oxygen-Diluent Tests}

The solid lines of Figs. 3 and 4 display flame spread results for n-butanol flames diluted by argon and helium, respectively. With argon, the transition to the pulsating flame spread regime occurs at the lower oxygen concentration of 21 percent of $\mathrm{O}_{2}\left(\mathrm{Fig} .3\right.$, curve b) compared to 25 percent $\mathrm{O}_{2}$ for nitrogen (Fig. 2, curve b). The flame-spread rates and pulsation behavior for the two corresponding transition conditions appear similar in the plotted curves for the two diluents. Since heat transfer ahead of the flame must have increased, the increased flame temperature resulting from argon's lower specific heat had more effect than the diminished thermal conductivity compared to nitrogen. These results are consistent with previous results showing enhanced spread with argon dilution for premixed gas ${ }^{14}$ and solid fuels. 15

It was initially anticipated that, owing to its equally low specific heat but higher thermal conductivity compared to argon, helium substitution would yield uniform, more rapid spread. Instead, at comparable conditions, the flame became more severely pulsating, with an increased frequency and instantaneous velocity. Compare the results for 25 percent $\mathrm{O}_{2}$ in $\mathrm{Fig}$. 4 , curve $b$, with the corresponding argon conditions in Fig. 3, curve a. During the retreat phase of each pulsating cycle, the flames lifted away from the pool surface nearly a full centimeter; during the advance phase they generally returned to a standoff distance less than $0.5 \mathrm{~mm}$. Flame thickness was increased as well. In contrast to other flames, gross asymmetries and some blowing around the pool surface developed at larger flame diameters. At times, portions of the flame advanced while other portions retreated. The flames had difficulty anchoring to the tray rim, but, after anchoring, burned conventionally. No discernable effect of diluent type on the oscillation frequency of the postspread pool fire was 
observed, although some intermittent flashes very near the tray rim could be seen for the hellum-diluted flames.

\subsection{Microgravity Tests}

Photographic observations of the microgravity flames showed that, in the uniform spread regime, flame shapes were as sketched in Fig. 5. Although the leading edges were virtually identical in appearance, the trailing shape of the microgravity flame was nearly parallel to the pool surface, indicating the suppression of buoyancy. Without a bright plume, more details on the pool surface were apparent on the top view camera, and revealed a reflection line about $1 \mathrm{~cm}$ ahead of, and moving with, the flame front, suggesting surface deformation and liquid convection ahead of the flame. When the reflection line reached and rebounded from the tray rim, it broke up and propagated inward as multiple rings.

The discrete data on Figs. 1 through 4 display the comparable microgravity, flame-spread data superposed on the normal-gravity data. For conditions where the corresponding normal-gravity flame spread was uniform, the microgravity spread was also uniform, at rates comparable to the normalgravity flames. As shown on these same figures, pulsating flame behavior in microgravity, where buoyant flows in both the liquid and gas phases are negligible, was never observed. Instead, independent of $\mathrm{O}_{2}$ concentration, fuel or diluent type, the initial conditions which gave rise to pulsating flame spread in normal gravity coincided with those causing extinguishment in a quiescent, microgravity environment. For example, when the $\mathrm{O}_{2}$ concentration was reduced to 17.5 percent with propanol- $\mathrm{O}_{2}-\mathrm{N}_{2}$ ( $\mathrm{Fig}$. 1), below 25 percent for butanol $-\mathrm{O}_{2}-\mathrm{N}_{2}$ ( $\mathrm{Fig} .2$ ), or 19 percent for butanol-O $\mathrm{O}_{2}$-argon ( $\mathrm{Fig} .3$ ), the conditions where pulsating spread was first clearly observed in normal gravity, flame initially identical to that observed in normal gravity was observed. However the flame did not propagate, lifting slowly away from the surface 
until it extinguished, indicating an extinction $11 \mathrm{mit}$. In the transition range between pulsating-uniform spread (e.g., propanol - 18 percent $0_{2}$, 82 percent $\mathrm{N}_{2}$; butanol -25 percent $\mathrm{O}_{2}, 75$ percent $\mathrm{N}_{2}$; butanol -21 percent $\mathrm{O}_{2}$. 79 percent Ar), the microgravity flame sometimes spread steadily, and sometimes extinguished, owing probably to slight differences in initial conditions or the usual imprecision of lean flammability-extinction conditions. The same extinction behavior was noted for the helium diluent, even though the normalgravity tests showed exaggerated pulsations.

In those cases where the flame spread to the edge of the tray, the microgravity flame subsequently collapsed bottom-up, l.e., toward the luminous region farthest from the pool, until the remaining flame was very thin and blue at a distance of 10 to $15 \mathrm{~mm}$ from the pool surface (see Fig. $5(\mathrm{~b})$ to (e)). After this collapse, the flame lifted very slightly away from the pool, and its luminosity steadily diminished, disappearing at low $\mathrm{O}_{2}$ concentrations before the end of the test.

A few tests were run with super-Tcc ethanol and methanol in air. Since flame spread for ethanol-air and methanol-air at room temperature is controlled by the premixed, combustible layers, ${ }^{2}$ and not by any buoyancy-related effects, no difference was found between normal and microgravity flame spread. Both were very rapid $(>1 \mathrm{~m} / \mathrm{sec})$ and similar in shape and color.

\section{DISCUSSION}

Previous experimental observations 2,3 suggested that the pulsating flame spread arises in part from a complicated, subsurface liquid flow structure with circulation around several centers, caused a temperature valley just ahead of the flame. The position of the pulsating flame front is such that it advances only to that location where the surface temperature corresponded to the flash point. The front can not propagate steadily because the amount of combustible vapor ahead of the flame was insufficient. A minimum combustion layer 
thickness was postulated such that while a barely combustible mixture may occur ahead of the flame, the amount of energy available for transfer to the liquid surface was insufficient to sustain further vaporization. Only when this thickness was exceeded, could flame spread be sustained.

The very shallow pools in our study should have prevented the complicated, subsurface flowfield; for pool depths less than $0.4 \mathrm{~cm}$, the flow is predicted to be in the viscous-dominated regime. 8 A ratio of liquid surface velocity due to thermocapillarity, $V_{\sigma}$, to that due to buoyancy, $V_{B}$, can be estimated by scale analysis 16 as:

$$
\frac{V_{\sigma}}{V_{B}}=\frac{h_{\sigma}(\partial T / \partial x)_{\sigma} \sigma^{\prime} / \mu}{g h_{B}^{3}(\partial T / \partial x)_{B} \rho^{\prime / \mu}}
$$

where $\sigma^{\prime}$ is the rate of change of surface tension with temperature, $g$ is the gravity level, $h$ is the depth of the heated layer, $\mu$ is the liquid viscosity and $\rho^{\prime}$ is the rate of change of liquid density with temperature. For shallow pools, $h_{\text {pool }}=h_{\sigma}=h_{B} ;$ measurements ${ }^{5}$ suggest $(\partial T / \partial x)_{\sigma} \cong 5(\partial T / \partial x)_{B}$, yielding $V_{\sigma} / V_{B} \cong 20$ for $n$-propanol at normal gravity. Having small buoyancy effects in the liquid even in normal gravity, pulsating spread was still observed. Therefore we conclude - in disagreement with some earlier work 2,3 - that this complicated, subsurface flow structure, attributed to buoyancy, is not required for pulsating spread.

Since buoyancy in the liquid is negligible for our pools in normal gravity, induced gas phase convection must be a key contributor to the development of pulsating spread (in agreement with Refs. 2 and 3 ). The gas phase flow in normal gravity simultaneously opposes flame spread and provides fresh oxidizer to the flame front. If this flow is absent, as in microgravity, the feed rate of oxidizer to the flame front is greatly reduced and may cause extinguishment at a higher $\mathrm{O}_{2}$ concentration in microgravity. Also, in the 
normal-gravity pulsating flame, products may accumulate near the flame front whenever the amount of combustible fuel vapor is less than the minimum combustible thickness and are swept away by the induced buoyant flow, permitting flame spread. In microgravity, the ability to clear away products via this mechanism is greatly diminished. The process may be further diminished by products carried ahead of the flame by thermocapillary-driven liquid motion and the gas-liquid, no-slip condition. The combined effects may lead to extinction.

Although gas phase buoyancy appears necessary for pulsating spread, there is a clear phenomenological distinction between pulsating spread and the familiar, hydrodynamically-induced oscillations of pool fires. Although the plume oscillated during spread at low $\mathrm{O}_{2}$ concentration, the observed flame spread rate was uniform. Further evidence is provided by the fact that $\mathrm{O}_{2}$ concentration and diluent type greatly affected the characteristic spread behavior, but had no discernable effect on the plume's oscillation frequency of the pool fire after spreading in normal gravity.

The detailed mechanisms of the asymmetrically pulsating, helium-diluted flames are beyond our current understanding. Clearly, the flash point temperature for helium-diluted environments is higher than that for the other diluents. This is evident not only from the observed spread behavior, but also from methanol droplet behavior in helium-diluted environments. 17 Ignition of the droplet was predicted and observed to be far more difficult in helium-diluted, as compared to nitrogen-diluted environments, due to more rapid thermal losses to the background. Similar to Ref. 17's observations, the helium-diluted flames were thick, indicating a smaller diffusion residence time compared with the chemical residence time. These effects yield a lowerthan-expected flame temperature, making sustained spread more difficult. 
The simllarity of normal and microgravity spread in the uniform regime indicates that (1) buoyancy-driven motion in elther phase had no influence on uniform flame spread, (2) radiation effects on spread were probably small for this scale experiment (the large change in flame height made no difference), and therefore (3) liquid conduction, gas phase conduction and possibly thermocaplliary-induced liquid motion were the controlling parameters.

The relative magnitude of these mechanisms can be examined individually. Liquid conduction is small and cannot control spread, relative to gas conduction by a comparison of the magnitude of gas and liquid conduction preheat lengths, as done for solid burning: $L_{g a s} / L_{l i q}=\left(\alpha_{g a s} / \alpha_{l} \mid i_{q}\right)\left[V_{F} /\left(u_{g}+V_{F}\right)\right] \gg 1$ where $\alpha=$ thermal diffusity and $u_{g}$ is the induced gas velocity. The earlier conclusion that gas phase conduction controlled spread in the uniform region was based on the observation of no liquid flow ahead of the uniformly spreading flame, ${ }^{1-3}$ an observation in conflict with this work and Ref. 5. If there were no liquid flow ahead of the flame, analogies to solid phase spread should be valid (we stress, for sub-Tcc uniform spread only where the spread velocities correspond to lean limit, premixed spread rates and not those of stratified, premixed systems), implying (1) solid phase flame spread equations should be predictive of spread rate away from the limiting oxygen index; (2) for increases in pool depth, flame spread should diminish; and (3) for constant $\left(T_{C C}-T_{p o o l}\right)$, flame spread rates should be comparable for different alcohols with sufficiently similar liquid and gas phase properties. Instead, (1) solld phase spread equations 18 underpredict by an order of magnitude the flame spread rates observed in this work and in Refs. 1 and 5 ; (2) uniform flame spread rate apparently increases with pool depth; 19 and (3) the spread rate for methanol is roughly 2 to 2.5 times that of $n$-propanol at $5{ }^{\circ} \mathrm{C}$ subcooling, 1,5 despite the similarity of their relevant thermodynamic and thermal transport properties. If some liquid convection precedes the flame, 
then this spread rate difference should be accountable to differences in liquid, convection-related properties such as $\sigma^{\prime}, \rho^{\prime}$, or $\mu$. For these fuels, $\sigma^{\prime}$ and $\rho^{\prime}$ are similar (slightly less, so flame spread actually should be reduced, for methanol), but $\mu_{p r o p}$ is roughly 3 times $\mu_{m e t h}$ and accounts for the difference in flame spread rates. Therefore we suggest, in agreement with Ref. 5, that liquid convection apparently controls spread in the uniform regime, while gas phase conduction is of secondary importance. Future microgravity tests with deep pools could determine if this liquid convection is attributable in part to buoyancy.

The postspread, microgravity flame behavior is consistent with theory20 which does not admit a solution for planar flames in a nearly convection-free, purely diffusive environment due to a lack of divergence (unlike droplets). Such theory does not account for second order effects, such as heat loss to a small diameter pool tray, but these effects appear to be small in our studies. An alternate explanation is that the flames extinguished due to heat loss and a lack of $\mathrm{O}_{2}$ transport to the flame region, independent of geometrical concerns.

5. CONCLUSIONS

The experiments reported in this paper investigated burning of alcohol fuels over 15-cm diameter pools in a free-fall facility under both microgravity and corresponding normal-gravity conditions. Results are reported as flame spread rates, determined from photographic observations of the flame diameter as a function of time.

Microgravity flame spread was always uniform. At conditions which caused pulsating spread in normal gravity, the microgravity flame extinguished. In the uniform spread regime, flame spread rates were similar in both gravity environments, indicating the buoyancy-driven motion in either phase is not important for the shallow pools which were investigated. Because pulsating 
spread was only observed in normal gravity, gas phase convection must be a key contributor to the development of pulsating spread.

Replacement of $\mathrm{N}_{2}$ diluent with argon shifts the pulsating flame spread onset to lower $\mathrm{O}_{2}$ concentrations (and presumably lower pool temperatures), as expected from diminished heat losses to the argon atmosphere. Helium dilution, on the other had, shifts the pulsating spread to higher $\mathrm{O}_{2}$ concentrations and intensifies the amplitude of the pulsations.

For potential application to spacecraft fire safety, it appears that the determination of the conditions yielding pulsating spread in normal gravity can be used to predict microgravity pool fire extinction limits, provided that gravity level is the only parameter that is changed.

\section{ACKNOWLEDGMENT}

The authors wish to express their gratitude to Professor F. Dryer for numerous discussions regarding the earlier Princeton research program and for advice regarding our present study.

\section{REFERENCES}

1. Akita, K.: 14th Symposium (International) on Combustion, p. 1075, The Combustion Institute, 1973.

2. Glassman, I. and Dryer, F.: Fire Saf. J. 3, $123(1980 / 81)$.

3. Dryer, F. and Newman, J.: Flame Spread over Liquid Fuels - The Mechanism of Flame Pulsation. Paper No. WSCI 76-48, Fall Mtg. of Western States of The Combustion Institute, La Jolla, CA, 1976.

4. Hirano, T., Suzuki, T., Mashiko, I., and Tanabe, N.: Combust. Sci. Technol. 22, 83 (1980).

5. I to, A., Masuda, D., and Saito, K.: A Study of Flame Spread Over Alcohol Using Holographic Interferometry. Accepted for publication Combust. Flame (1989). 
6. Mackinven, R., Hansel, J.G., and Glassman, I.: Combust. Sci. Technol. 1, $293(1970)$.

7. Torrance, K.: Combust. Sci. Technol. 3, 133 (1971).

8. Torrance, K.E. and Mahajan, R. L.: Combust. Sci. Technol. 10, 125 (1975).

9. Furuta, M., Humphrey, J.A.C., and Fernandez-Pello, A.C.: Phys. Chem. Hydrodyn. 6, $347(1985)$.

10. Lekan, J.: Microgravity Research in NASA Ground-Based Facilities, NASA TM-101397, 1989.

11. Concus, P.: J. Fluid Mech. 34, 481 (1968).

12. Burgoyne, J.H., Roberts, A.F., and Quinton, P.G.: Proc. Roy. Soc. A308, $39(1968)$.

13. Roberts, A.F.: 15th Symposium (International) on Combustion, p. 305, The Combustion Institute, 1975.

14. Coward, H.F., and Jones, G.W.: Limits of Flammabillty of Gases and Vapcrs Bulletin 503, U.S. Bureau of Mines, 1952.

15. McAlevy, R.F. and Magee, R.S.: 12th Symposium (International) on Combustion, p. 215, 1968.

16. Willlams, F.A.: Combustion Theory, 2nd ed., Chap. 12, Benjamin/Cummings, 1985.

17. Choi, M.Y., Cho, S.Y., Dryer, F.L., and Haggard, J.B.: Some Observationz on the Burning of Methanol Droplets in Microgravity Using Varlous Inert Gases. Fall Technical Meeting of the Eastern States Section of The Combustion Institute, Albany, NY, 1989.

18. De Ris, J.N.: 12th Symposium (International) on Combustion, p. 241, 1968.

19. Kanury, A.M.: Feasibility Study of Liquid Pool Burning in Reduced Gravity, NASA CR-159642, 1979.

20. Glassman, I.: Combustion, 2nd. ed., Chap. 6, Academic Press, 1987. 


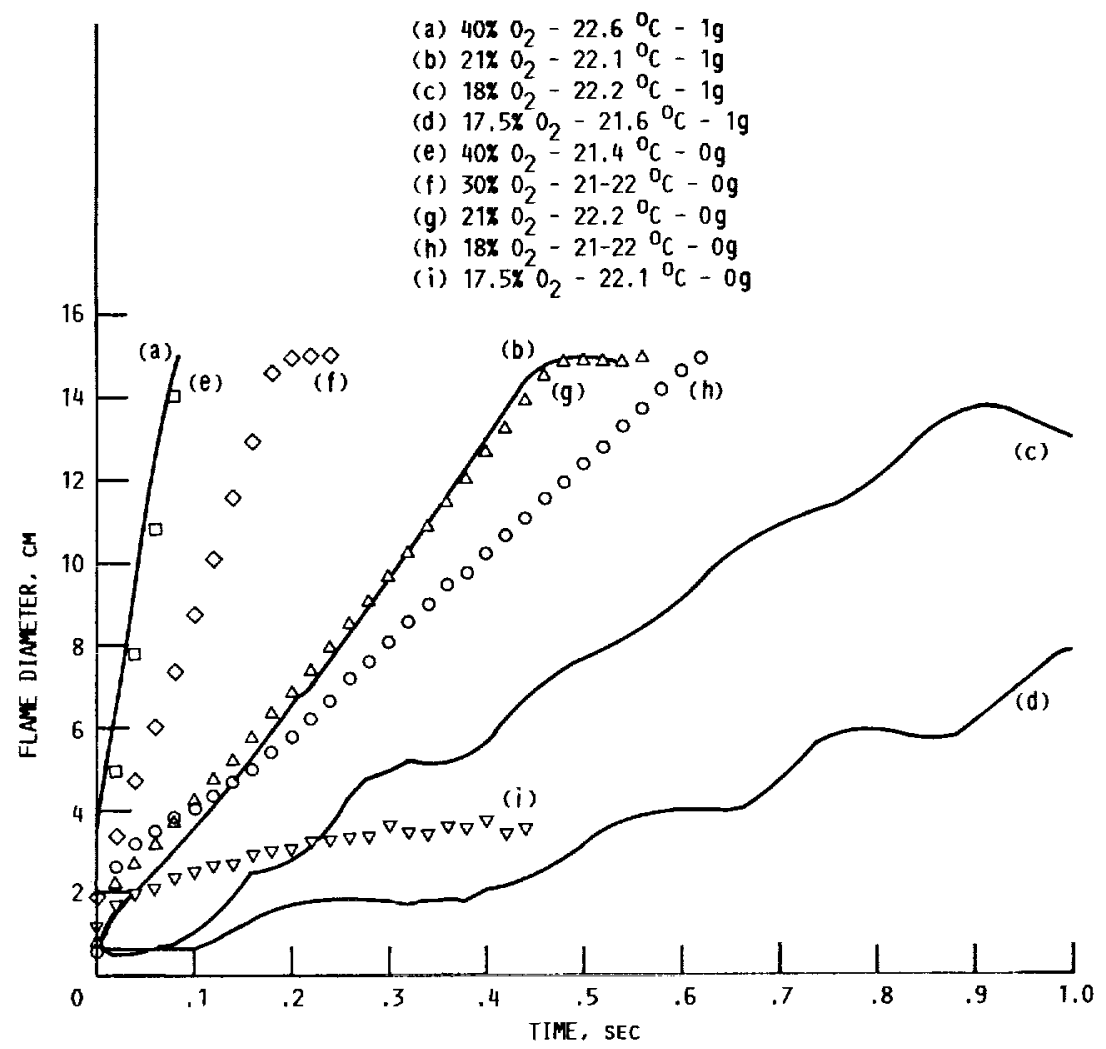

FIGURE 1. - FLAME SPREAD OVER PROPANOL $-\mathrm{O}_{2}-\mathrm{N}_{2}$, POOLS IN NORMAL AND MICROGRAVITY AS A FUNCTION OF $\mathrm{O}_{2}$ CONCENTRATION.

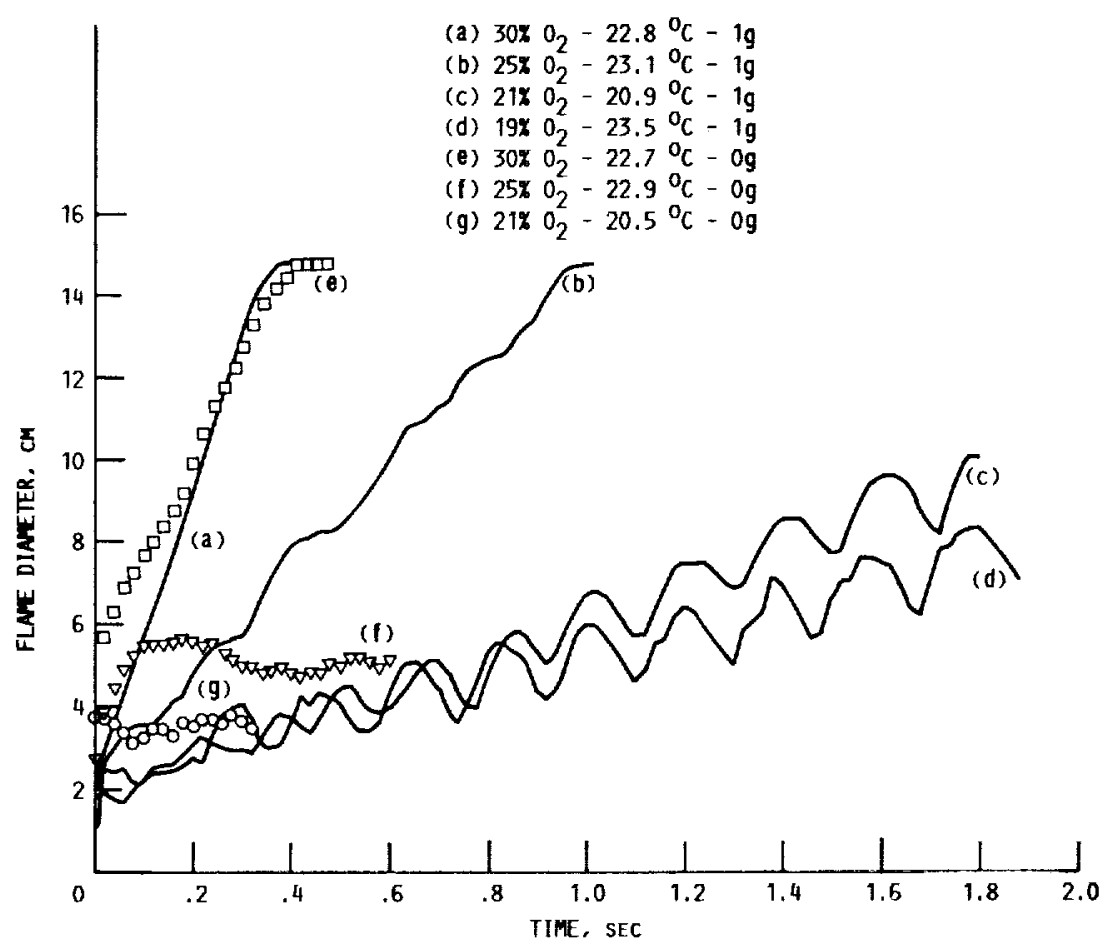

FiguRE 2. - FLAME SPREAD OVER BUTANOL $-\mathrm{O}_{2}-\mathrm{N}_{2}$ POOLS IN NORMAL AND MICROGRAVITY AS A FUNCTION OF $\mathrm{O}_{2}$ CONCENTRATION. 


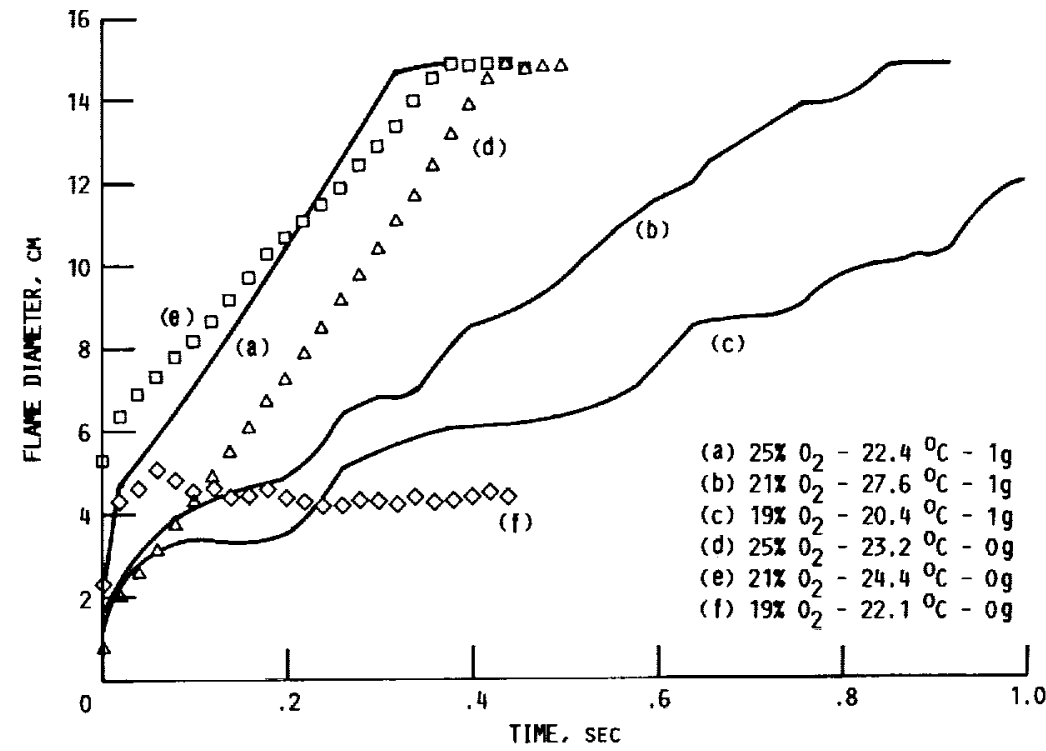

FIGURE 3. - FLAME SPREAD OVER BUTANOL $-\mathrm{O}_{2}$-AT POOLS IN NORMAL AND MICROGRAVITY AS A FUNCTION OF $\mathrm{O}_{2}$ CONCENTRATION (NOTE SCALE CHANGE FROM OTHER FIGURES).

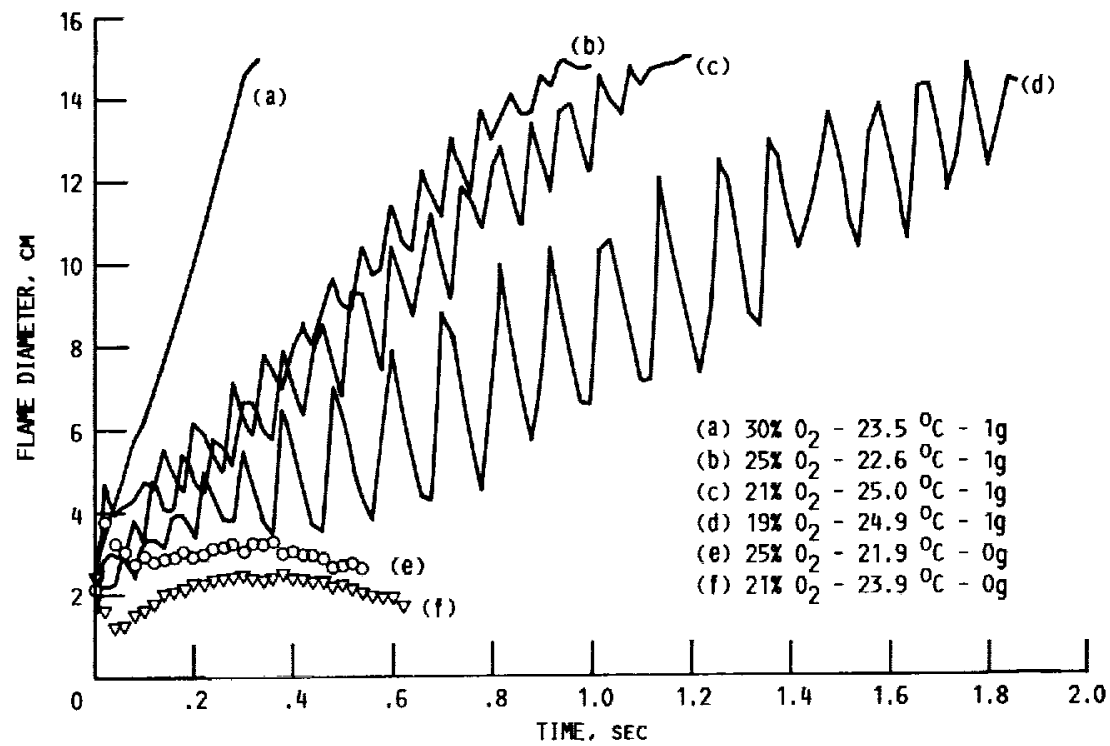

FIGURE 4. - FLAME SPREAD OVER BUTANOL-O $2_{2}$-He POOLS IN MORMAL AND MICROGRAVITY AS A FUNCTION OF $\mathrm{O}_{2}$ CONCENTRATION. 


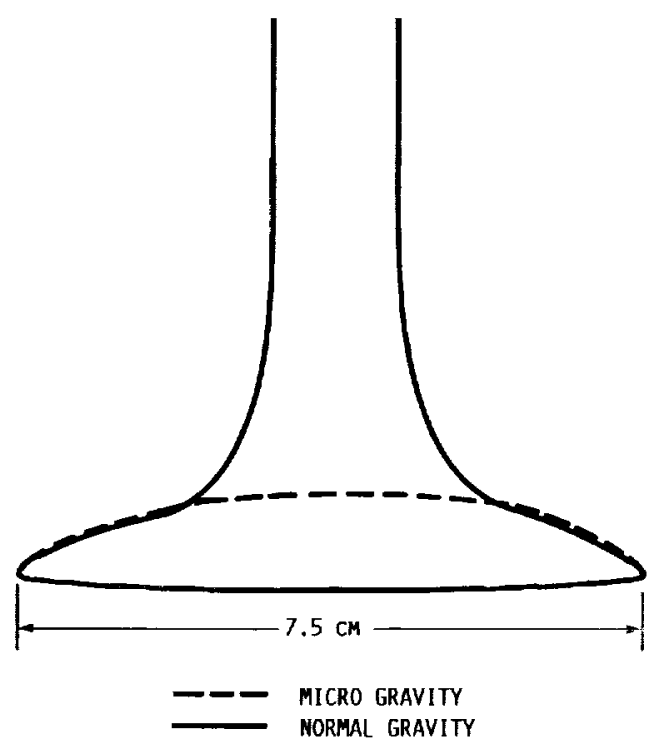

C

(b) PROPANOL $-30 \mathbf{Z}_{2}-70 \mathbf{X N}_{2}$, JUST AFTER SPREADING IN MICROGRAVITY.

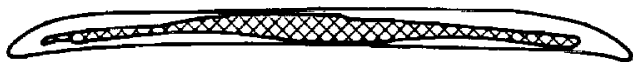

(c) PROPANOL $-30 \% 0_{2}-70 \mathrm{~N}_{2}, 0.1 \mathrm{sEC}$ AFTER SPREADING IN MICROGRAVITY.

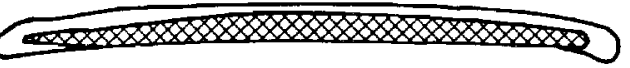

(d) PROPANOL-30\% $0_{2}-70 \% \mathrm{~K}_{2}, 0.3 \mathrm{SEC}$ AFTER SPREADING IN MICROGRAVITY.

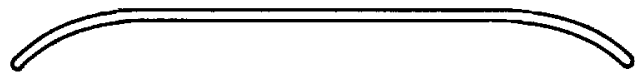

(e) PROPANOL $-30 \mathrm{KO}_{2}-70 \mathrm{KH}_{2}, 0.5$ SEC AFTER SPREADING IN MICROGRAVITY.

$\square$ YELLOH

$\underset{1 \mathrm{CM}}{\mathrm{S}}$

RED-BL.UE

BLUE AND MICROGRAVITY.

FIgURE 5, - FLANE APPEARANCE. 


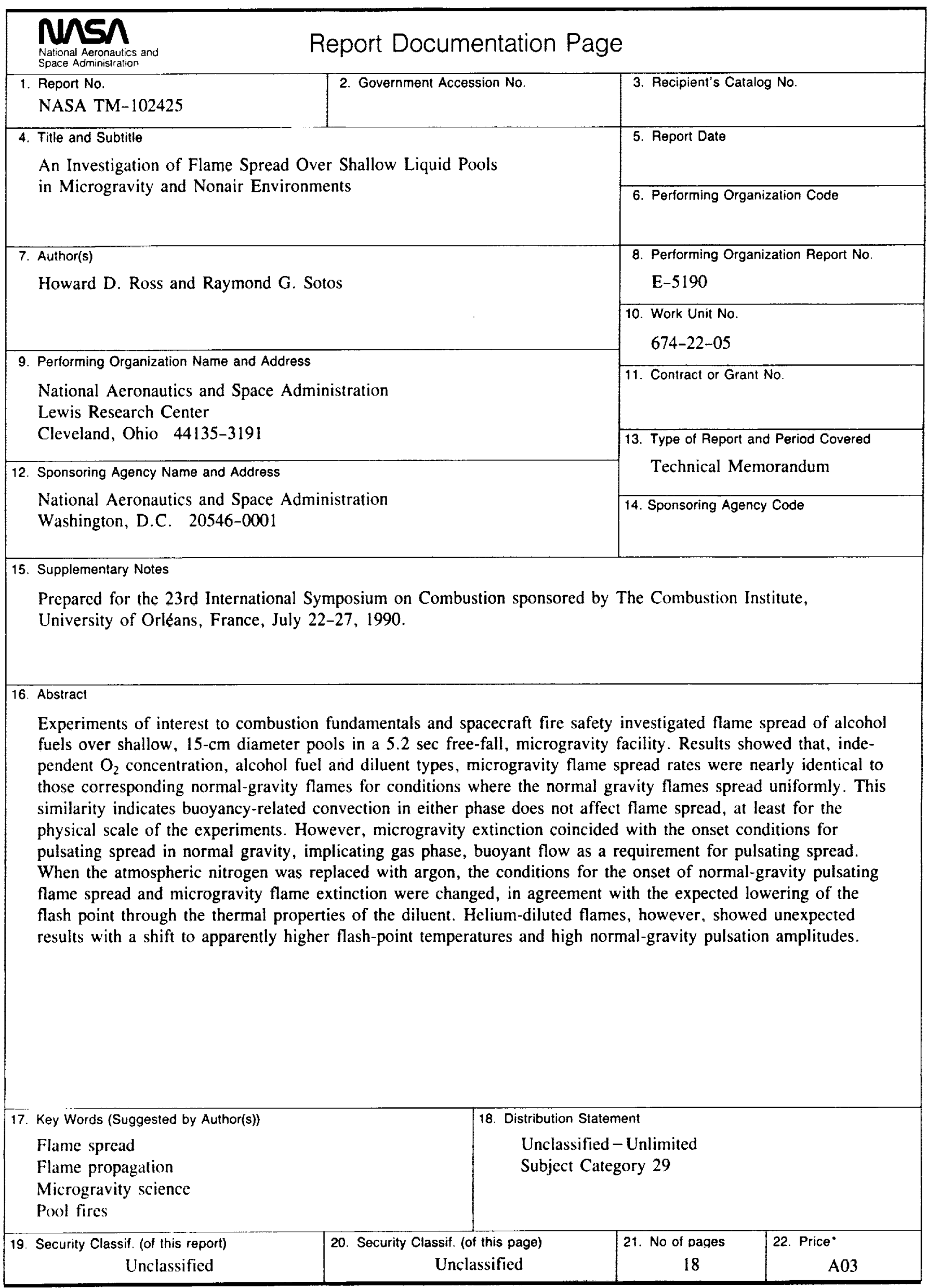

